\title{
Dietary patterns and their correlates among middle-aged and elderly Chinese men: a report from the Shanghai Men's Health Study
}

\author{
Hui Cai ${ }^{1}$, Wei Zheng ${ }^{1}$, Yong-Bing Xiang ${ }^{2}$, Wang Hong Xu${ }^{2}$, Gong Yang ${ }^{1}$, Honglan $\mathrm{Li}^{2}$ and Xiao Ou Shu ${ }^{1}$ \\ ${ }^{1}$ Department of Medicine, Vanderbilt Epidemiology Center and Vanderbilt-Ingram Cancer Center, Vanderbilt University, \\ Nashville, TN 37232-8300, USA \\ ${ }^{2}$ Department of Epidemiology, Shanghai Cancer Institute, Shanghai 200032, People's Republic of China
}

(Received 18 October 2006 - Revised 29 March 2007 - Accepted 3 April 2007)

Dietary patterns, which reflect the complexity of food preference, lifestyle and socio-economic status, may play a major role in health and longevity. Understanding dietary patterns and their correlates is important to the research of diet and health relationships. In the Shanghai Men's Health Study (SMHS) a total of 61582 men aged 40-74 were recruited between 2002 and 2006. Their food intake over the previous year was collected using a validated FFQ. Study participants $(75.6 \%)$ reported little or no change in meat and vegetable intake in the 5 years prior to recruitment. Using the baseline data of the SMHS, we assessed dietary patterns, as well as their relationship with socio-demographic and lifestyle factors and with prevalence of some chronic diseases. Three major dietary patterns, fruit-, vegetable- and meat-based diets, were identified in our population. Consumption of the fruit diet appeared to be more common among men who were older and more physically active, had higher income, and lower waist-to-hip ratio (WHR), while this diet was less common among manual labourers. The meat- or vegetable-based diets were less common among elderly men and more common among men with higher WHR. Dietary patterns appeared to be associated with the presence of health conditions. In general, subjects with a chronic disease were more likely to have the vegetable-based diet and less likely to have the fruit- or meat-based diets. Future studies of diet and health in this population will need to carefully take into account these potential confounders.

Dietary patterns: Socio-economic and lifestyle factors: Relationship: Factor analysis

The role of nutrients, foods and food groups in the causation of many chronic diseases has been extensively studied, and several foods and nutrients with beneficial or adverse effects have been identified ${ }^{1,2}$. Fewer studies have focused on whole diets or dietary patterns, which may also play an important role in the aetiology of many chronic diseases ${ }^{3-5}$. An important reason for this paucity of evidence is the difficulty in assessing or even defining a dietary pattern. Dietary pattern analysis, which reflects the complexity of dietary intake, has recently received considerable attention ${ }^{6}$.

Research on dietary patterns is warranted on several grounds. It has the ability to integrate the complex and subtle interactive effects of many dietary exposures and more closely approximates the biological activities of interdependent nutrients in vivo. Such research may resolve the problems generated by the multiple testing and high correlations that regularly occur in the analysis of individual foods or nutrients. Recommendations for disease prevention implicitly reflect the dietary pattern approach by emphasizing the simultaneous change of several dietary behaviours, such as increasing fruit and vegetable intake and decreasing meat intake ${ }^{7,8}$.

The primary goal of the present study is to define dietary patterns among a cohort of Chinese men between 40 and 74 years of age using data collected from a validated FFQ and to identify factors that correlate with those dietary patterns.

\begin{abstract}
Methods
Subjects

The current study is based on cross-sectional survey data obtained from the baseline survey of the Shanghai Men's Health Study (SMHS). SMHS is an ongoing populationbased prospective cohort study of 61582 men with a primary focus on the relationships of diet with cancer and other chronic diseases. The study has been conducted in eight communities in urban Shanghai since 2002. Subject recruitment started in March 2002 and was completed in June 2006. Using a roster provided by the community office, a total of 83125 permanent male residents between 40 and 74 years of age in the study communities were approached for the study by a trained interviewer (retired nurse or physician). The study was explained to each participant and consent to participate in the study was obtained. Afterwards, the interviewer administered a face-to-face interview (about $60 \mathrm{~min}$ long; mean $59.75 \mathrm{~min}$ ) using a structured questionnaire,
\end{abstract}


which included information on socio-economic status, living habits, physical activity and dietary habits. Also, study participants were asked whether they had ever been told by their doctors they have diabetes, hypertension, CVD, benign tumours or other chronic diseases. Of the eligible men approached for the study, 61582 participated, with a participation rate of $74.1 \%$. Among non-participants, there were 17513 refusals $(21 \cdot 1 \%), 1360$ men who had a serious health problem $(1.6 \%), 2252$ men who were absent during the study period $(3.1 \%)$ and 118 subjects with other miscellaneous reasons $(0 \cdot 1 \%)$. Non-participants were a little younger (51.3 (SD 8.4) years) than participants (54.9 (SD 9.7) years). The response rates were slightly varied by study districts (69.7-78.2\%). In the present study, the disease group was defined as having diabetes, hypertension, CVD or benign tumours, based on disease history at the baseline survey.

\section{Dietary information}

Dietary information was collected using a validated $\mathrm{FFQ}^{9}$. The FFQ included eighty-one food items and covered $88.8 \%$ of the commonly consumed foods in urban Shanghai. For each food item or food group, subjects were asked how frequently (daily, weekly, monthly, yearly or never) they consumed the food or food group, followed by a question on the amount of consumption in lians $(1$ lian $=50 \mathrm{~g})$ per unit of time over the past 12 months. For seasonal food consumption (mainly fruits and vegetables) an additional question about months of food consumption per year was asked. The daily nutrient intake used for analysis was then derived from the FFQ using the Chinese Food Composition Tables ${ }^{10}$. In addition, subjects were asked whether their intake of red meat, vegetables and fruits had changed during the past 5 years.

\section{Dietary pattern derivation}

Dietary patterns were derived using factor analysis ${ }^{11}$, with eighty-one individual foods or food groups entered into the analysis as the absolute amount of intake in $\mathrm{g} / \mathrm{d}$. The PROC FACTOR procedure in SAS version 9.1 (SAS Institute, Cary, NC, USA) was applied to perform the analysis. This procedure uses factor analysis and orthogonal rotation (varimax option in SAS) to derive non-correlated factors and to render it more easily interpretable. To determine which number of factors to retain, we examined both the scree plots and the factors themselves to see which set of factors most meaningfully described distinct food patterns. From these analyses, three factors were extracted. Factor loadings were calculated for each food or food group across the three factors (dietary patterns). Factors were thereby interpreted as dietary patterns and named after the food groups having the higher loading (loading $>0 \cdot 30$ ). These loadings can be considered as correlation coefficients between food groups and dietary patterns and they take values between -1 and +1 . A factor score was then calculated for each subject for each of the three factors, in which the standardized intakes of each of the eighty-one foods or food groups were weighted by their factor loadings and summed. The sums were standardized again ((score - mean score)/standard deviation of score).

\section{Statistical analysis}

Partial Pearson's correlation coefficients adjusted for energy intake were calculated between factor scores and food or nutrient intakes. The association of dietary factor scores with other lifestyle and anthropometric factors were estimated using a logistic regression model. Dietary factor scores were categorized into two categories by their medians, and lifestyle factors were categorized into quartiles or tertiles based on the distribution of the study population. To determine the relationship between dietary factors and lifestyle factors, as well as the prevalence of some chronic diseases, we estimated the adjusted OR and $95 \%$ CI for each quartile compared with the lowest quartile of each lifestyle factor. In these analyses, adjustment for age, education, income per person in a family, smoking status, alcohol consumption, physical activity, waist-to-hip ratio (WHR) and energy intake was made as appropriate (see footnotes to tables for details).

\section{Results}

A total of 61582 men aged 40-74 years were included in the present study. Among them, 22505 men had a history of selected disease, including diabetes (3874), hypertension (18392), CVD (5156) and benign tumours (1968). The basic characteristics of the study population are shown in Table 1. The average age of these participants was 55 (SD 9.7) years and $23.6 \%$ of the study participants had a college education. About $55 \%$ of subjects had per capita family income of less than 1000 yuan per month, and approximately half worked as manual labourers (mainly manufacturing workers). A majority of the men (59\%) were current smokers and one-third consumed alcoholic beverages regularly (at least three times per week for more than 6 months), while $36 \%$ participated in regular physical activity (at least once a week for a continuous 3 months).

We identified three major dietary patterns. Factor-loading matrices for the three dietary patterns are listed in Table 2. The higher the factor loading of a given food item, the greater the contribution of that food item to the specific factor. Dietary pattern I was heavily loaded with vegetables, such as legumes and leaf vegetables, and was labelled the 'vegetable diet'. Pattern II was mainly rich in fruits and was labelled the 'fruit diet'. Pattern III was characterized by high loadings on meat, poultry and animal parts (including heart, brain, tongue, intestine, etc.) and was labelled the 'meat diet'. These three patterns explain $79 \%$ of the variance of food intake.

Factor scores were calculated for all participants using factor loading of eighty-one foods or food groups. Their associations with food intake or nutrients are examined in Table 3. Correlation coefficients between factor scores and most of the nutrient or food intakes differed across the three dietary patterns. All dietary patterns were positively correlated with total energy intake. Therefore, correlations of other nutrients and food groups were adjusted for energy intake. All three dietary patterns, the fruit diet, the vegetable diet and the meat diet, showed high correlations with intake of their corresponding food groups, i.e. total fruit $(r 0 \cdot 81)$, total vegetable $(r$ 0.90) and total meat $(r$ 0.77). The meat diet had the strongest correlation with energy intake, a positive relation 
Table 1. General characteristics of all participants in the Shanghai Men's Health Study

\begin{tabular}{|c|c|c|c|}
\hline & $n$ & Mean/\% & SD \\
\hline Mean age (years) & 61582 & 54.9 & $9 \cdot 7$ \\
\hline Mean BMI $\left(\mathrm{kg} / \mathrm{m}^{2}\right)$ & 61459 & 23.7 & $3 \cdot 1$ \\
\hline Mean WHR & 61516 & 0.90 & 0.06 \\
\hline Mean energy intake (kJ) & 61582 & $7987 \cdot 1$ & $2030 \cdot 1$ \\
\hline \multicolumn{4}{|c|}{ Monthly per capita income (yuan; \%)* } \\
\hline$<1000$ & 33908 & $55 \cdot 2$ & \\
\hline $1000-2000$ & 21576 & $35 \cdot 1$ & \\
\hline$>2000$ & 5971 & $9 \cdot 7$ & \\
\hline \multicolumn{4}{|l|}{ Education (\%) } \\
\hline Elementary/under & 4102 & $6 \cdot 8$ & \\
\hline Middle school & 20369 & $33 \cdot 6$ & \\
\hline High school & 21885 & $36 \cdot 0$ & \\
\hline Above high school & 14362 & $23 \cdot 6$ & \\
\hline \multicolumn{4}{|l|}{ Occupation (\%)† } \\
\hline Office worker & 16344 & $26 \cdot 6$ & \\
\hline Clerical & 13488 & 21.9 & \\
\hline Worker and farmer & 31679 & 51.5 & \\
\hline \multicolumn{4}{|l|}{ Regular smoking (\%) } \\
\hline Ever & 42870 & $69 \cdot 6$ & \\
\hline Currentł & 36103 & $58 \cdot 6$ & \\
\hline \multicolumn{4}{|c|}{ Regular alcohol consumption (\%) } \\
\hline Ever & 20753 & $33 \cdot 7$ & \\
\hline Current‡ & 18032 & $29 \cdot 3$ & \\
\hline \multicolumn{4}{|c|}{ Regular tea consumption (\%) } \\
\hline Ever & 41322 & $67 \cdot 1$ & \\
\hline Currentł & 39457 & $64 \cdot 1$ & \\
\hline \multicolumn{4}{|c|}{ Regular ginseng consumption (\%) } \\
\hline Ever & 19916 & $32 \cdot 3$ & \\
\hline Current $\ddagger$ & 17173 & $27 \cdot 9$ & \\
\hline \multicolumn{4}{|c|}{ Regular physical activity (\%) } \\
\hline No & 39686 & 64.4 & \\
\hline Yes & 21896 & $35 \cdot 6$ & \\
\hline
\end{tabular}

WHR, waist-to-hip ratio.

${ }^{*} 1$ US $\$=8.2$ yuan.

† Office worker: professor, technician, lawyer, doctor, teacher, administrators. Worker and farmer: manual labour workers in factories, construction and farms.

¥ Men in 'Current' group were included in the 'Ever' group.

with consumption of fat and protein, and a negative relation with consumption of carbohydrates and dietary fibre. This diet also had relatively weak correlations with vitamins and minerals ( $r<0.31$, except sodium), as compared with the other two dietary patterns. The vegetable diet showed a very weak association with fat, but strong positive correlations with dietary fibre, vitamin $\mathrm{A}$, vitamin $\mathrm{C}$, vitamin $\mathrm{E}$, folic acid, calcium and iron. The fruit diet had a moderate positive association with vitamins and minerals.

The relationship between the dietary patterns and selected population characteristics were examined by estimating the OR for being in the upper half of the score of each dietary pattern (Table 4). Dietary patterns varied according to socioeconomic and lifestyle factors, with the fruit diet showing the biggest variations. The fruit diet was more commonly consumed by those people who had higher income and higher education. It was also related to healthier lifestyle habits, such as no smoking, no alcohol consumption, more physical activity and low WHR. In contrast, people with higher consumptions of meat were more likely to be smokers and to drink more alcohol. It is interesting that the vegetable diet was not associated with income or education, but was, except for high WHR, moderately related to healthier lifestyle habits, such as no smoking, no alcohol consumption and
Table 2. Factor loading for three major food patterns at baseline for 54195 male adults in the Shanghai Men's Health Study*

\begin{tabular}{|c|c|c|c|}
\hline Food or food group & $\begin{array}{c}\text { Factor I } \\
\text { (vegetable) }\end{array}$ & $\begin{array}{l}\text { Factor II } \\
\text { (fruit) }\end{array}$ & $\begin{array}{c}\text { Factor III } \\
\text { (meat) }\end{array}$ \\
\hline Rice & 7 & -5 & -4 \\
\hline $\begin{array}{l}\text { Noodles, steamed bread, } \\
\text { dumplings and other wheat } \\
\text { foodstuffs }\end{array}$ & 4 & -6 & 17 \\
\hline All kinds of desserts & -5 & 25 & 9 \\
\hline Bread & -2 & $31^{\star}$ & 6 \\
\hline Pork chops & 0 & 8 & 24 \\
\hline Pork ribs & 5 & 9 & $31^{*}$ \\
\hline Pig's feet & 2 & -1 & $36^{\star}$ \\
\hline Pig's hamhock & -1 & -1 & $32^{\star}$ \\
\hline Fresh pork (fat) & 0 & -7 & 14 \\
\hline Fresh pork (lean) & 10 & 8 & 27 \\
\hline Fresh pork (mixture) & 5 & -2 & $34^{*}$ \\
\hline Pig liver & 2 & -1 & 27 \\
\hline $\begin{array}{l}\text { Animal parts (heart, brain, } \\
\text { tongue, tripe, intestine) }\end{array}$ & 3 & -4 & $33^{*}$ \\
\hline Beef, lamb & 9 & 4 & $35^{\star}$ \\
\hline Egg, duck egg & 7 & 18 & 19 \\
\hline Chicken & 6 & 18 & $40^{\star}$ \\
\hline Duck, goose & 8 & 15 & $36^{\star}$ \\
\hline $\begin{array}{l}\text { Saltwater fish (e.g. yellow } \\
\text { croaker, hair tail) }\end{array}$ & 19 & 14 & $31^{*}$ \\
\hline $\begin{array}{l}\text { Freshwater fish (e.g. silver carp, } \\
\text { bream, crucian carp, etc.) }\end{array}$ & 19 & 19 & 20 \\
\hline Rice field eel or river eel & 6 & 8 & $32^{\star}$ \\
\hline Shrimp, crab, etc. & 16 & 26 & 30 \\
\hline Conch, etc. & 10 & 5 & 24 \\
\hline Fresh milk & 0 & $34^{\star}$ & -1 \\
\hline Soya milk, powdered soya milk† & 6 & 6 & 6 \\
\hline Bean curd & 24 & 3 & 23 \\
\hline $\begin{array}{l}\text { Fried bean curd, vegetarian } \\
\text { chicken, bean curd cake } \\
\text { and other kinds of bean } \\
\text { products excluding fresh } \\
\text { bean curd }\end{array}$ & 27 & 1 & $30^{*}$ \\
\hline Dried soyabeans & 11 & 8 & 13 \\
\hline $\begin{array}{l}\text { Mung bean, red bean and } \\
\text { other dried beans }\end{array}$ & 10 & 20 & 7 \\
\hline Soyabean sprouts & 22 & -1 & 29 \\
\hline Mung bean sprouts & 21 & 0 & 27 \\
\hline Greens, Chinese greens & $31^{*}$ & 7 & -1 \\
\hline Spinach & $32^{\star}$ & 1 & 17 \\
\hline Green cabbage & $31^{\star}$ & 6 & 3 \\
\hline $\begin{array}{l}\text { Chinese cabbage, bak } \\
\text { choi cabbage }\end{array}$ & $35^{\star}$ & 3 & 7 \\
\hline Cauliflower & $35^{\star}$ & 8 & 7 \\
\hline Chinese celery & $39^{*}$ & 6 & 5 \\
\hline Snow pea shoots & 29 & 11 & 11 \\
\hline Eggplant & $37^{\star}$ & 2 & 1 \\
\hline Wild rice stems & $39^{\star}$ & 6 & 8 \\
\hline Asparagus lettuce & $34^{\star}$ & 0 & 12 \\
\hline Potato & $37^{\star}$ & 9 & 8 \\
\hline Wax gourd & $41^{\star}$ & 13 & 0 \\
\hline Cucumber & $40^{*}$ & 19 & 2 \\
\hline Luffa & $33^{\star}$ & 8 & 2 \\
\hline $\begin{array}{l}\text { Fresh mushroom, fresh } \\
\text { xianggu mushroom }\end{array}$ & $32^{*}$ & 20 & 11 \\
\hline Fresh red and green pepper & $34^{\star}$ & -3 & 15 \\
\hline Tomato & $40^{\star}$ & 26 & 1 \\
\hline Bamboo shoots & $31^{*}$ & 14 & 13 \\
\hline Lotus root & 26 & 13 & 3 \\
\hline Head of garlic & 21 & 3 & 10 \\
\hline Garlic and garlic shoots & $36^{\star}$ & -8 & 15 \\
\hline Onion & $30^{\star}$ & 7 & 8 \\
\hline Chinese chives & $38^{*}$ & -6 & 14 \\
\hline Green onion & 21 & 6 & 18 \\
\hline White turnip & $34^{*}$ & 12 & 2 \\
\hline Carrot & 25 & 16 & -2 \\
\hline
\end{tabular}


Table 2. Continued

\begin{tabular}{|c|c|c|c|}
\hline Food or food group & $\begin{array}{c}\text { Factor I } \\
\text { (vegetable) }\end{array}$ & $\begin{array}{l}\text { Factor II } \\
\text { (fruit) }\end{array}$ & $\begin{array}{c}\text { Factor III } \\
\text { (meat) }\end{array}$ \\
\hline Baby soya bean & $37^{*}$ & 9 & 8 \\
\hline Fresh peas & 29 & 14 & 9 \\
\hline Fresh broad beans & 22 & 9 & 5 \\
\hline Yard long bean & $45^{\star}$ & 5 & 1 \\
\hline $\begin{array}{l}\text { Green bean } \\
\text { (four-season bean) }\end{array}$ & $47^{\star}$ & 11 & 2 \\
\hline $\begin{array}{l}\text { Hyacinth bean/snow } \\
\text { peas (Dutch pea) }\end{array}$ & $35^{\star}$ & 9 & 9 \\
\hline Garland chrysanthemum & $35^{\star}$ & 6 & 6 \\
\hline Shepherd's-purse & $31^{*}$ & 10 & 12 \\
\hline Clover & $33^{\star}$ & 3 & 13 \\
\hline Amaranth & $39^{\star}$ & 5 & 4 \\
\hline Apples & 14 & $48^{\star}$ & -3 \\
\hline Pears & 15 & $42^{*}$ & 0 \\
\hline $\begin{array}{l}\text { Tangerines, oranges, } \\
\text { grapefruits }\end{array}$ & 14 & $50^{\star}$ & 0 \\
\hline Bananas & 8 & $35^{\star}$ & -2 \\
\hline Grapes & 13 & $39^{\star}$ & 3 \\
\hline Watermelon & 14 & $45^{\star}$ & 0 \\
\hline Peaches & 12 & $36^{*}$ & 1 \\
\hline $\begin{array}{l}\text { Other fruits (e.g. strawberries, } \\
\text { cantaloupe) }\end{array}$ & 14 & $35^{\star}$ & 1 \\
\hline $\begin{array}{l}\text { Black and white edible } \\
\text { tree fungi }\end{array}$ & 5 & 9 & 1 \\
\hline Dried xianggu mushroom & 12 & 14 & 4 \\
\hline Sea tangle & 19 & 7 & 10 \\
\hline Sea laver & 11 & 9 & 9 \\
\hline Milk powder & 1 & 6 & 0 \\
\hline Preserved fruits & -2 & 20 & 7 \\
\hline Peanuts & 11 & 10 & 13 \\
\hline
\end{tabular}

${ }^{*}$ Factor loadings are multiplied by 100 and rounded to the nearest integer. Only factor loadings $>30$ are listed.

† If the powdered kind is used to make the drink, the amount consumed will be the amount of the drink.

regular physical activity, as compared with the other two dietary patterns.

Table 5 shows the covariate-adjusted OR of benign tumours and chronic non-communicable diseases, such as diabetes, hypertension and CVD, by dietary pattern. Higher consumption of fruit and meat were more prevalent in the healthy men. However, these two dietary patterns had inverse relationships with diabetes: the OR for prevalence of diabetes in the highest quartile for the fruit diet was 0.39 , but for the highest quartile of the meat diet the OR was 1.57 , compared to the lowest quartiles of the fruit or meat diets, respectively. The vegetable diet was more commonly consumed by people with all four types of chronic diseases, and the highest OR for diabetes was 2.30 for the highest quartile, compared to the lowest quartile.

\section{Discussion}

In the present study, we identified three distinct dietary patterns from a large group of Chinese men who participated in the SMHS, and we evaluated their relationship with socioeconomic and lifestyle factors. Other studies have reported the same patterns ${ }^{12}$ or similar patterns ${ }^{13-15}$ for men and women, often showing two to three dietary patterns in Western populations. Few studies have considered more than three patterns ${ }^{16-18}$.
Table 3. Correlation coefficients between dietary factors and food groups or nutrients*

\begin{tabular}{lccr}
\hline & Vegetable diet & Fruit diet & Meat diet \\
\hline All vegetables & 0.9049 & 0.2147 & -0.0158 \\
All fruits & 0.1882 & 0.8119 & -0.1245 \\
All meat & 0.0855 & 0.2071 & 0.7753 \\
Energy 1† & 0.3209 & 0.2668 & 0.4475 \\
Energy 2† & 0.3264 & 0.1932 & 0.5046 \\
Fat & 0.0273 & 0.1972 & 0.6613 \\
Protein & 0.3484 & 0.3363 & 0.6184 \\
Carbohydrate & -0.0787 & 0.0130 & -0.6186 \\
Dietary fibre & 0.6337 & 0.4305 & -0.0120 \\
Vitamin A & 0.5755 & 0.3706 & 0.1356 \\
Carotene & 0.6723 & 0.3427 & -0.0668 \\
Vitamin B1 & 0.2941 & 0.2316 & 0.2699 \\
Vitamin B2 & 0.4503 & 0.5305 & 0.3138 \\
Vitamin C & 0.8399 & 0.3523 & -0.0146 \\
Vitamin E & 0.4685 & 0.2704 & 0.2974 \\
Folic acid & 0.7231 & 0.3158 & 0.0572 \\
Isoflavone & 0.3223 & 0.0102 & 0.2915 \\
Calcium & 0.5549 & 0.4015 & 0.1748 \\
Sodium & 0.3979 & 0.4899 & 0.3954 \\
Iron & 0.5837 & 0.2804 & 0.1880 \\
\hline * Correlation for all food groups and nutrients, other than energy 1 and \\
energy 2, are partial correlations, adjusted for energy 2. All corre- \\
lation coefficients are statistically significant $(P<0.0001)$. \\
†Energy 1 came from all foods and food groups. Energy 2 came from \\
$\quad$ both foods and alcohol consumption. & & \\
& & &
\end{tabular}

Several researchers have reported dietary patterns derived from FFQ in cohort studies using factor analysis. Although several distinct patterns were reported, two patterns were relatively dominant and were first introduced by Slattery et al. in $1998^{19}$. The first is a Prudent (Mediterranean, or vegetablefruit diet) pattern characterized by high intake of vegetables, legumes, fruits and unrefined cereals. The other is a Western (Traditional, or red meat diet) pattern characterized by high intake of fat, meat and refined grain. Harvard researchers also derived these two dietary patterns from two large cohort studies, the Nurses' Health Study and the Health Professionals' Follow-up Study, and examined the relationship between these major dietary patterns and the risk of $\mathrm{CHD}^{20}$, type II diabetes ${ }^{21}$, and biochemical markers of obesity and CHD risk ${ }^{22}$. A negative association of the 'Prudent diet' was demonstrated in all of these studies. Additionally, 'Cake and sweet', 'Takeaway food' and 'Southern' patterns have been identified in the other studies ${ }^{18,23,24}$.

The meat diet found in the present study is similar to the Western pattern reported in other studies. The other two patterns, the vegetable and fruit diets, appear to be consistent with the set of food items that are part of Slattery et al.'s 'Prudent' pattern ${ }^{19}$. Interestingly, in the present study fruit and milk were part of the same dietary pattern, while the vegetable pattern did not include any dairy products. This indicates that correlation between fruit and milk is higher than that between vegetables and milk. The present result is consistent with that found in the study of Park et al. ${ }^{12}$, in which three distinct dietary patterns, 'Fat and meat', 'Vegetables' and 'Fruit and milk' were identified by factor analysis.

Food intakes can be handled in different ways in a factor analysis. Some studies have used individual food items and/ or pre-defined food groups for factor analysis. Others aggregated food items into food groups based on the similarity of 
Table 4. Dietary patterns in association with demographic and lifestyle factors in the Shanghai Men's Health Study*

\begin{tabular}{|c|c|c|c|c|c|c|}
\hline & \multicolumn{2}{|c|}{ Vegetable diet } & \multicolumn{2}{|c|}{ Fruit diet } & \multicolumn{2}{|c|}{ Meat diet } \\
\hline & OR & $95 \% \mathrm{Cl}$ & OR & $95 \% \mathrm{Cl}$ & OR & $95 \% \mathrm{Cl}$ \\
\hline \multicolumn{7}{|l|}{ Age } \\
\hline$<46$ & 1.0 & & 1.0 & & 1.0 & \\
\hline $46-50$ & 1.07 & $1.02,1 \cdot 13$ & 0.97 & $0.92,1.03$ & 0.82 & $0.78,0.87$ \\
\hline $51-58$ & 0.94 & $0.90,1.00$ & 0.92 & $0.87,0.97$ & 0.74 & $0.70,0.78$ \\
\hline$>58$ & 0.78 & $0.74,0.82$ & 0.97 & $0.91,1.02$ & 0.55 & $0.52,0.59$ \\
\hline$P$ for trend & $<0.001$ & & 0.362 & & $<0.001$ & \\
\hline \multicolumn{7}{|l|}{ WHR } \\
\hline$<0.85$ & $1 \cdot 0$ & & 1.0 & & $1 \cdot 0$ & \\
\hline $0.85-0.89$ & $1 \cdot 11$ & $1 \cdot 06,1 \cdot 18$ & 1.02 & $0.96,1.07$ & 1.01 & $0.96,1.07$ \\
\hline $0.90-0.93$ & 1.22 & $1 \cdot 16,1 \cdot 28$ & 0.97 & $0.92,1.02$ & 1.03 & $0.97,1.08$ \\
\hline$>0.94$ & 1.28 & $1 \cdot 22,1 \cdot 35$ & 0.87 & $0.83,0.92$ & $1 \cdot 11$ & $1.06,1 \cdot 18$ \\
\hline$P$ for trend & $<0.001$ & & $<0.001$ & & 0.002 & \\
\hline \multicolumn{7}{|c|}{ Monthly per capita income (yuan)† } \\
\hline$<1000$ & 1.0 & & 1.0 & & 1.0 & \\
\hline$=1000$ & 1.03 & $0.99,1.07$ & 1.51 & $1.45,1.57$ & 1.01 & $0.97,1.05$ \\
\hline$>1000$ & 1.07 & $1.01,1.14$ & 2.08 & $1.95,2.22$ & $1 \cdot 19$ & $1 \cdot 12,1.28$ \\
\hline$P$ for trend & 0.011 & & $<0.001$ & & $<0.001$ & \\
\hline \multicolumn{7}{|l|}{ Education } \\
\hline Elementary/under & 1.0 & & 1.0 & & 1.0 & \\
\hline Middle school & $1 \cdot 30$ & $1.20,1.40$ & 1.59 & $1.46,1.73$ & 1.27 & $1.16,1.39$ \\
\hline High school & 1.32 & $1.22,1.44$ & $2 \cdot 30$ & $2 \cdot 11,2.50$ & 1.46 & $1.34,1.60$ \\
\hline Above high school & 1.39 & $1.27,1.52$ & 3.19 & $2.91,3.50$ & 1.55 & $1.41,1.71$ \\
\hline$P$ for trend & $<0.001$ & & $<0.001$ & & $<0.001$ & \\
\hline \multicolumn{7}{|l|}{ Occupation } \\
\hline Professional & 1.0 & & 1.0 & & 1.0 & \\
\hline Clerical & 1.07 & $1.01,1.13$ & 0.85 & $0.80,0.90$ & 0.92 & $0.87,0.97$ \\
\hline Worker and farmer & 1.01 & $0.96,1.07$ & 0.79 & $0.75,0.84$ & 0.87 & $0.82,0.92$ \\
\hline$P$ for trend & 0.601 & & $<0.001$ & & $<0.001$ & \\
\hline \multicolumn{7}{|l|}{ Regular smoking } \\
\hline Never & 1.0 & & 1.0 & & 1.0 & \\
\hline Former & 0.97 & $0.91,1.03$ & 0.84 & $0.79,0.89$ & 1.02 & $0.95,1.09$ \\
\hline Current & 0.83 & $0.79,0.86$ & 0.50 & $0.48,0.52$ & 1.45 & $1.38,1.51$ \\
\hline$P$ for trend & $<0.001$ & & $<0.001$ & & $<0.001$ & \\
\hline \multicolumn{7}{|c|}{ Regular alcohol consumption } \\
\hline Never & 1.0 & & 1.0 & & 1.0 & \\
\hline Former & 0.85 & $0.78,0.93$ & 0.70 & $0.64,0.76$ & 0.69 & $0.63,0.75$ \\
\hline Current & 1.03 & $0.99,1.07$ & 0.57 & $0.55,0.60$ & 1.70 & $1.63,1.77$ \\
\hline$P$ for trend & 0.203 & & $<0.001$ & & $<0.001$ & \\
\hline \multicolumn{7}{|c|}{ Regular tea consumption } \\
\hline Never & 1.0 & & 1.0 & & 1.0 & \\
\hline Former & $1 \cdot 12$ & $1.01,1 \cdot 15$ & $1 \cdot 16$ & $1.05,1.29$ & 0.91 & $0.81,1.02$ \\
\hline Current & 1.10 & $1.06,1.15$ & 1.11 & $1.07,1.16$ & 1.22 & $1.17,1.27$ \\
\hline$P$ for trend & $<0.001$ & & $<0.001$ & & $<0.001$ & \\
\hline \multicolumn{7}{|l|}{ Regular physical activity } \\
\hline No & 1.0 & & 1.0 & & 1.0 & \\
\hline Yes & 1.30 & $1.25,1.35$ & 1.55 & $1.49,1.61$ & 1.06 & $1.02,1.11$ \\
\hline \multicolumn{7}{|l|}{ Family history of cancer } \\
\hline No & $1 \cdot 0$ & & $1 \cdot 0$ & & $1 \cdot 0$ & \\
\hline Yes & 1.05 & $1.01,1.09$ & 1.00 & $0.96,1.04$ & 1.01 & $0.97,1.05$ \\
\hline
\end{tabular}

WHR, waist-to-hip ratio.

${ }^{*}$ Adjusted for factors in this table mutually.

$\dagger 1$ US $\$=8.2$ yuan.

nutrient profiles or culinary usage in order to reduce the number of variables considered and minimize the withinperson variation in consumption of individual foods ${ }^{13,25}$. The resulting number of food group variables used in factor analyses differs widely from eight ${ }^{26}$ to about $100^{18}$. In the present study we used factor analysis based on pre-defined individual foods or food groups obtained directly from the FFQ, which in turn reflects the specific consumption habits of the Chinese population under study.

In the present study, the relationship between the three dietary patterns and age and health characteristics is similar to what has been reported in some earlier studies. Sanchez-Villegas et al. $^{27}$ reported a negative association between age and a Western dietary pattern, while Tseng \& De Vellis ${ }^{28}$ reported a positive association between age and a vegetable-fruit pattern. In the present study, age was negatively associated with the meat diet, but not associated with the fruit-based diet. We found that more educated people had higher scores for all dietary patterns and people with high income had higher scores for the meat and fruit diets, associations which have also been observed in other studies ${ }^{23,28}$. No association between the vegetable diet and levels of income and 
Table 5. Relation between prevalence of selected common diseases and dietary patterns*

\begin{tabular}{|c|c|c|c|c|c|c|c|c|c|c|}
\hline \multirow[b]{2}{*}{ Quartiles } & \multicolumn{2}{|c|}{ History of disease† } & \multicolumn{2}{|c|}{ Diabetes ( $n$ 3874) } & \multicolumn{2}{|c|}{ Hypertension ( $n 18$ 392) } & \multicolumn{2}{|c|}{ CVD ( $n$ 5156) $\ddagger$} & \multicolumn{2}{|c|}{ Tumour $(n$ 1968)§ } \\
\hline & OR & $95 \% \mathrm{Cl}$ & OR & $95 \% \mathrm{Cl}$ & OR & $95 \% \mathrm{Cl}$ & OR & $95 \% \mathrm{Cl}$ & OR & $95 \% \mathrm{Cl}$ \\
\hline \multicolumn{11}{|l|}{ Vegetable diet } \\
\hline$\leq-0.60$ & 1.0 & & 1.0 & & 1.0 & & 1.0 & & 1.0 & \\
\hline$-0.61-$ & $1 \cdot 12$ & $1 \cdot 07,1 \cdot 18$ & 1.24 & $1 \cdot 11,1.37$ & $1 \cdot 13$ & $1.07,1.19$ & 1.05 & $0.96,1.15$ & $1 \cdot 13$ & $0.98,1.29$ \\
\hline$-0.20-$ & 1.23 & $1 \cdot 17,1.30$ & 1.59 & $1.43,1.76$ & 1.22 & $1 \cdot 16,1.29$ & 1.05 & $0.96,1.16$ & 1.26 & $1 \cdot 10,1.44$ \\
\hline $0.36-$ & 1.37 & $1 \cdot 30,1.45$ & $2 \cdot 30$ & $2.07,2.56$ & 1.33 & $1.26,1.41$ & $1 \cdot 27$ & $1.15,1.40$ & 1.35 & $1 \cdot 18,1.56$ \\
\hline$P$ for trend & $<0.001$ & & $<0.001$ & & $<0.001$ & & $<0.001$ & & $<0.001$ & \\
\hline \multicolumn{11}{|l|}{ Fruit diet } \\
\hline$\leq-0.59$ & 1.0 & & 1.0 & & 1.0 & & 1.0 & & 1.0 & \\
\hline$-0.60-$ & 0.92 & $0.88,0.97$ & 0.78 & $0.71,0.85$ & 0.93 & $0.88,0.98$ & 1.01 & $0.92,1 \cdot 11$ & 1.01 & $0.88,1.15$ \\
\hline$-0.12-$ & 0.88 & $0.84,0.93$ & 0.53 & $0.48,0.59$ & 0.89 & $0.84,0.94$ & 1.01 & $0.91,1 \cdot 11$ & 1.01 & $0.88,1.16$ \\
\hline $0.43-$ & 0.81 & $0.77,0.86$ & 0.39 & $0.35,0.44$ & 0.83 & $0.78,0.88$ & 1.02 & $0.92,1.13$ & 0.96 & $0.82,1 \cdot 11$ \\
\hline$P$ for trend & $<0.001$ & & $<0.001$ & & $<0.001$ & & 0.002 & & 0.556 & \\
\hline \multicolumn{11}{|l|}{ Meat diet } \\
\hline$\leq-0.48$ & $1 \cdot 0$ & & 1.0 & & 1.0 & & 1.0 & & $1 \cdot 0$ & \\
\hline$-0.49-$ & 0.90 & $0.86,0.94$ & 1.15 & $1.04,1 \cdot 26$ & 0.87 & $0.82,0.91$ & 0.78 & $0.72,0.85$ & 1.00 & $0 \cdot 88,1 \cdot 13$ \\
\hline$-0.10-$ & 0.82 & $0.78,0.86$ & 1.26 & $1.14,1.39$ & 0.78 & $0.73,0.82$ & 0.64 & $0.58,0.70$ & 0.93 & $0.81,1.06$ \\
\hline $0.42-$ & 0.76 & $0.72,0.81$ & 1.57 & $1.40,1.76$ & 0.70 & $0.66,0.74$ & 0.65 & $0.58,0.72$ & 0.86 & $0.74,1.00$ \\
\hline$P$ for trend & $<0.001$ & & $<0.001$ & & $<0.001$ & & $<0.001$ & & 0.034 & \\
\hline
\end{tabular}

${ }^{*}$ Adjusted for age, education, income, energy intake, physical activity, ever smoking and ever drinking.

†Disease group was composed of diabetes, hypertension, CVD and tumour.

$\ddagger$ Including acute myocardial infarction, CHD and stroke.

$\S$ Benign tumour only.

occupation was found in the present study. This may be explained by the fact that vegetables are cheaper and more affordable than fruits and animal foods in China. The most commonly consumed vegetables in the study population are greens, Chinese greens, bean curd and soya products. Although these vegetables are less commonly consumed in Western countries, they contain many phytochemicals that have been shown to be beneficial to cardiovascular health and reduce cancer risk ${ }^{29}$. In the present study, the meat diet was positively associated with WHR, current smoking status and alcohol consumption, but negatively associated with being a manual labourer. However, fruit and vegetable diets were negatively associated with having an office job, current smoking status and alcohol consumption, but positively associated with physical activity, similar to findings from earlier studies ${ }^{19,23,28}$. Although our fruit and vegetable patterns showed relationships with many socioeconomic and lifestyle factors similar to other studies, only the fruit pattern was negatively associated with WHR and alcohol consumption. It seems that the fruit diet was more strongly associated with healthy lifestyles than the vegetable diet. Thus the 'healthy diet' in the present study, the fruit diet, could be extended to a 'healthy profile' that included no smoking, no or low alcohol consumption, more physical activity, and that was more frequently observed in men with higher education.

We did not find any association of a family history of cancer on dietary patterns. However, we did find a negative association between the fruit diet and chronic diseases. Associations of prevalence of chronic diseases showed the opposite trend for the meat diet compared to the vegetable diet. A strongly inverse association was found between the meat diet and all kinds of diseases, and a positive association was found between the vegetable diet and chronic diseases. A possible explanation of the present finding is that men changed their dietary behaviour after the diagnosis of a chronic disease. We found that among those men with a chronic disease, $25.5 \%$ had decreased their red meat intake and $12.6 \%$ had increased their vegetable intake in the previous year, as compared to their food intake 5 years ago. In contrast, among healthy men, $13.7 \%$ had reduced their intake of red meat and $8.4 \%$ had increased their intake of vegetables. Another possible reason is men with high income had more protein intake than those men with low income in the present study. Relative adequacy of protein intake may be a factor contributing to this inverse relationship since some studies found an inverse association between hypertension and protein intake $^{30,31}$. In the present study, the association between prevalence of chronic disease and meat diet was attenuated by adjusting for protein intake. Some studies have reported associations between dietary patterns and prevalence or incidence of some chronic diseases, although the findings are inconsistent $^{17,24,25,32-37}$. Further investigation of the association of dietary patterns at baseline with subsequent cancer and other chronic disease incidence are planned for the SMHS.

Family income is an important confounding factor in the analysis of association between dietary factor and chronic disease in the present study. We found a positive association of family income and prevalence of chronic disease (OR 1.10, $95 \%$ CI $1 \cdot 06,1 \cdot 13)$, especially for hypertension. This association was absent when adjusted for age, education, energy intake and physical activity. The present result is slightly different from Colhoun's study in developed countries, in which the conclusion established that lower socioeconomic status adults had higher mean blood pressure and higher rates of hypertension in developed countries, with the gradient stronger and more consistently obtained in women than in men $^{38}$.

The strengths of the present study include the populationbased study design, high response rate and the use of a validated FFQ. There are some limitations in the present study. First, recall error is a problem inherent in the study of dietary 
intake and responses in the present study may have been confounded by selective under- or over-reporting of particular food items ${ }^{39}$. The factor analysis approach itself involves several arbitrary decisions, which have been discussed elsewhere ${ }^{20,23}$ and which include the consolidation of food items into food groups, the number of factors to be extracted, the method of rotation and even the labelling of the components ${ }^{3,40}$. We did a sensitivity analysis using the whole data set and using data from only 'healthy' men without hypertension, CVD, diabetes or tumours. The same factors were extracted from these two data sets with only minor differences in factor loadings. The present study was based on a study conducted in urban Shanghai, one of most industrialized cities in China. Therefore, the results may not be generalized to other Chinese populations, especially the population in rural areas.

In conclusion, three main dietary patterns were identified for middle-aged men of urban Shanghai. Their dietary patterns were associated with age, education, prevalence of major chronic diseases and health behaviours in the present study. The present findings support the hypothesis that dietary patterns are influenced by interrelated socioeconomic and other lifestyle factors. It is important to consider these variables as potential confounding factors in the future analysis of diet and disease associations in the SMHS and other studies.

\section{Acknowledgements}

The study was supported by grant number RO1 CA82729 from the US National Institutes of Health. The authors thank the participants and staff members of the SMHS for their important contributions. The authors also thank Ms Brandy Sue Venuti for her assistance in manuscript preparation. H. C. contributed to the analysis and interpretation of the data, and writing of the manuscript. W. Z. contributed to experimental design, interpretation of the data and critical revision of the manuscript. Y.-B. X., W. H. X., G. Y. and H. L. were closely involved in implementation and performing quality control of this study. X. O. S. contributed to the experimental design and critical revision of the manuscript and also obtained funding. None of the authors had any conflict of interest.

\section{References}

1. Riboli E \& Norat $\mathrm{T}$ (2001) Cancer prevention and diet: opportunities in Europe. Public Health Nutr 4 (2B), 475-484.

2. Willett WC (1998) Nutritional Epidemiology, 2nd ed. New York: Oxford University Press.

3. Hu FB (2002) Dietary pattern analysis: a new direction in nutritional epidemiology. Curr Opin Lipidol 13, 3-9.

4. Osler M, Heitmann BL, Gerdes LU, Jorgensen LM \& Schroll M (2001) Dietary patterns and mortality in Danish men and women: a prospective observational study. Br J Nutr 85, 219-225.

5. Newby PK, Muller D, Hallfrisch J, Andres R \& Tuker KL (2004) Food patterns measured by factor analysis and anthropometric changes in adults. Am J Clin Nutr 80, 504-513.

6. Trichopoulou A \& Critselis E (2004) Mediterranean diet and longevity. Eur J Cancer Prev 13, 453-456.
7. Ledikwe JH, Wright HS, Mitchell DC, Miller CK \& Jensen GL (2004) Dietary pattern of rural older adults are associated with weight and nutritional status. J Am Geriatr Soc 52, 589-595.

8. Kant AK, Schatzkin A, Graubard BI \& Schairer C (2000) A prospective study of diet quality and mortality in women. JAMA 283, 2109-2115.

9. Villegas R, Yang G, Liu D, Xiang YB, Cai H, Zheng W \& Shu XO (2007) Validity and reproducibility of the food frequency questionnaire used in the Shanghai Men's Health Study. $B r J$ Nutr 7, 1-8.

10. Yang YX, Wang GY \& Pan XC (editors) (2002) China Food Composition Tables 2002. Beijing: Beijing University Medical Press.

11. Kleinbaum DG, Kupper LL \& Muller KE (1988) Applied Regression Analysis and Other Multivariable Methods, pp. 595-640 Boston, MA: PWS Publishing Company.

12. Park SY, Murphy SP, Wilkens LR, Yamamoto JF, Sharma S, Hankin JH, Henderson BE \& Kolonel LN (2005) Dietary patterns using the Food Guide Pyramid groups are associated with sociodemographic and lifestyle factors: the multiethnic cohort study. $J$ Nutr 135, 843-849.

13. Lopez-Garcia E, Schulze MB, Fung TT, Meigs JB, Rifai N, Manson JE \& Hu FB (2004) Major dietary patterns are related to plasma concentrations of markers of inflammation and endothelial dysfunction. Am J Clin Nutr 80, 1029-1035.

14. Khani BR, Ye W, Terry P \& Wolk A (2004) Reproducibility and validity of major dietary patterns among Swedish women assessed with a food-frequency questionnaire. J Nutr 134, 1541-1545.

15. Bamia C, Orfanos P, Ferrari P, et al. (2005) Dietary patterns among older Europeans: the EPIC-Elderly study. Br J Nutr 94, 100-113.

16. Newby PK, Muller D, Hallfrisch J, Andres R \& Tucker KL (2004) Food patterns measured by factor analysis and anthropometric changes in adults. Am J Clin Nutr 80, 504-513.

17. Sieri S, Krogh V, Pala V, Muti P, Micheli A, Evangelista A, Tagliabue G \& Berrino F (2004) Dietary patterns and risk of breast cancer in the ORDET cohort. Cancer Epidemiol Biomarkers Prev 13, 567-572.

18. Mishra G, Ball K, Arbuckle J \& Crawford D (2002) Dietary patterns of Australian adults and their association with socioeconomic status: results from the 1995 National Nutrition Survey. Eur J Clin Nutr 56, 687-693.

19. Slattery ML, Boucher KM, Caan BJ, Potter JD \& Ma KN (1998) Eating patterns and risk of colon cancer. Am J Epidemiol 148, $4-16$.

20. Hu FB, Rimm EB, Stampfer MJ, Ascherio A, Spiegelman D \& Willett WC (2000) Prospective study of major dietary patterns and risk of coronary heart disease in men. Am J Clin Nutr 72, 912-921.

21. van Dam RM, Rimm EB, Willett WC, Stampfer MJ \& Hu FB (2002) Dietary patterns and risk for type 2 diabetes mellitus in U.S. men. Ann Intern Med 136, 201-209.

22. Fung TT, Willett WC, Stampfer MJ, Manson JE \& Hu FB (2001) Dietary patterns and the risk of coronary heart disease in women. Arch Intern Med 161, 1857-1862.

23. Schulze MB, Hoffmann K, Kroke A \& Boeing H (2001) Dietary patterns and their association with food and nutrient intake in the European Prospective Investigation into Cancer and Nutrition (EPIC)-Potsdam study. Br J Nutr 85, 363-373.

24. Tseng M, Breslow RA, DeVellis RF \& Ziegler RG (2004) Dietary patterns and prostate cancer risk in the National Health and Nutrition Examination Survey Epidemiological Follow-up Study cohort. Cancer Epidemiol Biomarkers Prev 13, 71-77.

25. Hoffmann K, Zyriax BC, Boeing H \& Windler E (2004) A dietary pattern derived to explain biomarker variation is strongly associated with the risk of coronary artery disease. Am J Clin Nutr 80, 633-640. 
26. Marchioni DM, Latorre Mdo R, Eluf-Neto J, Wunsch-Filho V \& Fisberg RM (2005) Identification of dietary patterns using factor analysis in an epidemiological study in Sao Paulo. Sao Paulo Med J 123, 124-127.

27. Sanchez-Villegas A, Delgado-Rodriguez M, Martinez-Gonzalez MA, De Irala-Estevez J \& Seguimiento Universidad de Navarra Group (2003) Gender, age, socio-demographic and lifestyle factors associated with major dietary patterns in the Spanish Project SUN (Seguimiento Universidad de Navarra). Eur J Clin Nutr 57, 285-292.

28. Tseng M \& DeVellis RF (2001) Fundamental dietary patterns and their correlates among US whites. JAm Diet Assoc 101, 929-932.

29. Manach C, Williamson G, Morand C, Scalbert A \& Remesy C (2005) Bioavailability and bioefficacy of polyphenols in humans. I. Review of 97 bioavailability studies. Am J Clin Nutr 81, Suppl., 230S-242S.

30. Liu K, Ruth KJ, Flack J, Jones-Webb R, Bruke G, Savage PJ \& Hulley SB (1996) Blood pressure in young blacks and whites: relevance of obesity and lifestyle factors in determining differences: the CARDIA study. Circulation 93, 60-66.

31. Kihara M, Fujikawa J, Ohtaka M, Mano M, Nara Y \& Horie R (1984) Interrelationships between blood pressure, sodium, potassium, serum cholesterol and protein intake in Japanese. Hypertension 6, 736-774.

32. Mizoue $\mathrm{T}$, Yamaji $\mathrm{T}$, Tabata $\mathrm{S}$, Yamaguchi $\mathrm{K}$, Ogawa $\mathrm{S}$, Mineshita M \& Kono S (2006) Dietary patterns and glucose tolerance abnormalities in Japanese men. $J$ Nutr 136, $1352-1358$
33. Pitsavos C, Milias GA, Panagiotakos DB, Xenaki D, Panagopoulos G \& Stefanadis C (2006) Prevalence of selfreported hypertension and its relation to dietary habits, in adults; a nutrition \& health survey in Greece. BMC Public Health 6, 206-214.

34. Terry P, Hu FB, Hansen J \& Wolk A (2001) Prospective study of major dietary patterns and colorectal cancer risk in women. Am J Epidemiol 154, 1143-1149.

35. Fung T, Hu FB, Fuchs C, Giovannucci E, Hunter DJ, Stampfer MJ, Colditz GA \& Willett WC (2003) Major dietary patterns and the risk of colorectal cancer in women. Arch Inter Med 163, 309-314.

36. Schulze MB, Hoffmann K, Kroke A \& Boeing H (2003) Risk of hypertension among women in the EPIC-Potsdam Study: comparison of relative risk estimates for exploratory and hypothesis-oriented dietary patterns. Am J Epidemiol 158, 365-373.

37. Fung TT, Stampfer MJ, Manson JE, Rexrode KM, Willett WC \& Hu FB (2004) Prospective study of major dietary patterns and stroke risk in women. Stroke 35, 2014-2019.

38. Colhoun HM, Hemingway H \& Poulter NR (1998) Socioeconomic status and blood pressure: an overview analysis. J Human Hypertens 12, 101-110.

39. Lissner L, Heitmann BL \& Bengtsson C (2000) Population studies of diet and obesity. Br J Nutr 83, Suppl. 1, S21-S24.

40. Martinez ME, Marshall JR \& Sechrest L (1998) Invited Commentary: Factor analysis and the search for objectivity. Am J Epidemiol 148, 17-19. 